\title{
PRIVACIDADE FÍSICA REFERENTE À EXPOSIÇÃO E MANIPULAÇÃO CORPORAL: PERCEPÇÃO DE PACIENTES HOSPITALIZADOS ${ }^{1}$
}

\author{
Jussara Simone Lenzi Pupulim², Namie Okino Sawada ${ }^{3}$
}

\begin{abstract}
1 Artigo extraído da tese - Satisfação do Paciente Hospitalizado com sua Privacidade Física: construção e validação de um instrumento de medida, 2009.

${ }^{2}$ Doutora em Enfermagem Fundamental. Professor Adjunto do Departamento de Enfermagem da Universidade Estadual de Maringá. Paraná, Brasil. E-mail: jslpupulim@bol.com.br

${ }^{3}$ Doutora em Enfermagem. Professor Associado da Escola de Enfermagem de Ribeirão Preto da Universidade de São Paulo. Centro Colaborador da OMS para o desenvolvimento da Pesquisa em Enfermagem. São Paulo, Brasil. E-mail: sawada@ eerpusp.br
\end{abstract}

RESUMO: Estudo descritivo utilizando Análise de Conteúdo, que objetivou descrever a percepção de privacidade física do paciente hospitalizado referente à exposição e manipulação corporal. Participaram 34 pacientes internados e após análise das entrevistas emergiram quatro categorias temáticas, fundamentadas em teorias da privacidade: dignidade e respeito, intimidade e toque, espaço pessoal e territorial, autonomia. Os pacientes admitem desconforto e constrangimento ante a nudez e toque corporal, sobretudo nas partes íntimas, apontando fatores comportamentais que contribuem ou não para a proteção e manutenção da privacidade física. $\mathrm{O}$ respeito emerge como aspecto mais importante, seguido pela necessidade de controle pessoal sobre as situações de contravenção à sua privacidade. Para eles privacidade está interconectada com dignidade e respeito, demanda relação de intimidade e toque corporal, depende da delimitação do espaço pessoal/territorial e da garantia de autonomia. Esses conceitos e atitudes são interligados e indispensáveis ao resguardo da privacidade física no contexto hospitalar.

DESCRITORES: Assistência ao paciente. Hospitalização. Privacidade. Autonomia pessoal. Territorialidade.

\section{PHYSICAL PRIVACY REGARDING BODY EXPOSURE AND MANIPULATION: PERCEPTION OF HOSPITALIZED PATIENTS}

\begin{abstract}
The aim of this descriptive study, using Content Analysis, is to describe hospitalized patients' perceptions of physical privacy regarding having their bodies exposed and physically manipulated. Thirty-four hospitalized patients took part in the study. From interview analysis, four thematic categories based on privacy theories emerged: dignity and respect; intimacy and touch; personal and territorial space; and autonomy. Patients admit discomfort and embarrassment at nudity and bodily touch, especially their private parts, mentioning behavioral factors which contribute or not to protect and maintain physical privacy. Respect emerges as the most important aspect, followed by the need for personal control over situations which violate privacy. To these patients, privacy is linked to dignity and respect, demands a combination of intimacy and bodily touch, depends on outlining the personal/territorial space, and depends on a guarantee of autonomy. These concepts/attitudes are connected and essential to protecting physical privacy in the hospital.

DESCRIPTORS: Patient care. Hospitalization. Privacy. Personal autonomy. Territoriality.
\end{abstract}

\section{LA PERCEPCIÓN DE LA PRIVACIDAD DEL PACIENTE HOSPITALIZADO EN LO QUE SE REFIERE A LA EXPOSICIÓN Y MANEJO CORPORAL}

RESUMEN: Estudio descriptivo, usando el Análisis de Contenido, con el objetivo de describir la percepción de la privacidad del paciente hospitalizado en lo que se refiere a la exposición y manejo corporal. Los participantes del estudio fueron 34 pacientes hospitalizados. Del análisis de las entrevistas emergieron cuatro categorías temáticas, basadas en las teorías de la privacidad: dignidad y respeto, intimidad y tacto, espacio personal y territorial, autonomía. Los pacientes admiten que sufren molestias y vergüenza ante la desnudez y tacto corporal, sobre todo en las partes íntimas, señalando factores de comportamiento que contribuyen o no para la protección de la privacidad física. El respeto surge como el aspecto más importante, seguido por la necesidad de control personal sobre las situaciones de abuso a su privacidad. Para esos pacientes, la privacidad está interrelacionada con la dignidad y el respeto, exige relación de intimidad y tacto corporal, depende de la delimitación del espacio personal/territorial y de la garantía de autonomía. Esos conceptos y actitudes están interrelacionados y son esenciales para la protección de la intimidad física en el hospital.

DESCRIPTORES: Atención al paciente. Hospitalización. Privacidad. Autonomía personal. Territorialidad. 


\section{INTRODUÇÃO}

No cuidado à saúde a violação da privacidade da pessoa pode ocorrer de formas variadas e em diferentes níveis, como da informação, do espaço pessoal e territorial, do corpo, no campo psicológico e moral. É indiscutível o mérito disso, contudo, se questiona quais são os limites e as normas para a ação dos profissionais, tendo em vista os direitos do paciente e que expor e tocar o corpo, além das informações obtidas, é inerente a assistência à saúde.

É interessante apontar a ausência de leis específicas direcionadas à privacidade referente ao acesso físico dos usuários dos sistemas de saúde. Os códigos de ética preveem o dever do profissional e o direito do paciente à privacidade, assim como a Constituição Brasileira e a Declaração Universal dos Direitos Humanos, porém não são explícitos e nem há fiscalização, parecendo mais normas e recomendações, ${ }^{1}$ talvez porque o limite entre o necessário e o excesso seja muito tênue e difícil de ser determinado. Privacidade envolve estar em contato ou sem contato com os outros, pois o desejo por interação social, ou não, altera-se com o tempo e as circunstâncias, configurandose, portanto, como um processo de regulação da fronteira interpessoal onde o espaço pessoal e o comportamento territorial são mecanismos usados para controlar o quanto se está acessível. ${ }^{2}$

Em outras palavras, privacidade é o afastamento voluntário e temporário de uma pessoa da sociedade em geral, por meios físicos ou psicológicos, podendo ser reivindicada para determinar "quando", "como", e "em que extensão" a informação sobre si pode ser comunicada a outrem. ${ }^{3}$ De fato, os indivíduos estão constantemente engajados num processo de ajustamento pessoal, havendo uma contínua re-ponderação entre o desejo por privacidade e o desejo por revelar-se e comunicar-se. ${ }^{3}$

Por conseguinte, no hospital, privacidade abrange o "direito do cliente hospitalizado de preservar seu corpo da exposição e manipulação por outrem, sendo que o desrespeito a esse direito caracteriza a sua invasão", 4:389 visto que seu primeiro nível é o da pessoa, do próprio corpo. Privacidade física implica quão se está acessível corporalmente a outra pessoa, incluindo o espaço entre si e o outro, e quão se pode controlar de acesso. A demarcação do perímetro territorial permite manter e impor limites à invasão, todavia, o poder de incursão dos outros às vezes é superior ao de defesa da pessoa, pois a internação enfraquece as barreiras por ela construídas para o resguardo da intimidade.
Pouco tem se avaliado e discutido sobre privacidade física na saúde, especialmente na enfermagem, posto que na prática diária se observam situações desconfortáveis e de conflito por falhas à sua proteção, sobretudo quando envolve a região íntima. No entanto, adverte-se que as ações da enfermagem devem ter como referência os princípios éticos, os quais servem de "[...] linha orientadora na actuação de toda a equipe". 5:167 Nesse sentido, ao focar o seu agir profissional na relação interpessoal, concorda-se que a enfermagem deve "[...] valorizar e respeitar os valores, crenças e desejos individuais", ${ }^{5: 167}$ em defesa da autonomia e do respeito pelas escolhas das pessoas, tendo em vista acima de tudo o princípio da dignidade, pois quando se invade a privacidade do doente invariavelmente se fere sua dignidade. ${ }^{5}$

Diante do exposto e da suposição que sua invasão é desagradável aos pacientes, conhecer como eles concebem privacidade física no hospital contribuirá para a adoção de condutas e medidas de proteção durante a assistência. Afinal, como melhorar o resguardo da privacidade física quando se desconhecem os aspectos intervenientes, as implicações da violação, as preferências e a necessidade por privacidade das pessoas internadas? Em função da carência de investigações sobre privacidade relacionada à esfera corporal no contexto de saúde brasileiro, o objetivo deste artigo é descrever a percepção de privacidade física do paciente internado referente à exposição e manuseio corporal durante a assistência. Como parte da tese (doutorado) intitulada - Satisfação do paciente hospitalizado com sua privacidade física: construção e validação de um instrumento de medida -, esse estudo forneceu subsídios para a definição do construto privacidade física e subsequente elaboração dos itens do instrumento de medida construído.

\section{MÉTODO}

Estudo descritivo com abordagem qualitativa, empregando a Análise de Conteúdo, ${ }^{6}$ modalidade temática, para evidenciar, nas falas dos sujeitos, os caracteres comuns que denotaram algum significado revelando a percepção sobre privacidade física relativa à exposição e manipulação corporal. Foi realizado após aprovação do Comitê Permanente de Ética em Pesquisa Envolvendo Seres Humanos da Universidade Estadual de Maringá, Parecer $N^{\circ} 084 / 2007$, anuência e assinatura do Termo de Consentimento Livre e Esclarecido pelos pacientes participantes do estudo conforme Resolução No 196/96 do CNS/MS. 
O número de entrevistas realizadas durante a internação, não foi pré-definido, prosseguindo até se obter a saturação das informações. Em seguida, as informações foram lidas repetidamente e os dados obtidos separados, classificados e codificados (sujeito com número e fala com letra), para então serem reunidos conforme a similaridade, presença e frequência, seguindo critério semântico. ${ }^{6} \mathrm{~A}$ identificação das categorias baseou-se nos aspectos e características comuns observados nas falas dos sujeitos, à luz do referencial teórico adotado, cujos fundamentos são discutidos nas teorias da privacidade..$^{2-3}$

Em síntese, tais teorias preconizam que privacidade é o afastamento temporário e voluntário de um indivíduo da sociedade em geral $^{3} \mathrm{e}$ que consiste em controlar o quão se está acessível (física e psicologicamente) aos outros. ${ }^{2}$ Para que isso aconteça são necessários mecanismos (espaço pessoal e território, abarcando manejo da interação e fronteira pessoal) e condições básicas (solidão/reserva, intimidade, anonimato), além das funções exercidas pela privacidade (autonomia e auto-avaliação implicando dignidade e respeito). ${ }^{2-3}$ Destaca-se que o sistema de regulação da privacidade é dinâmico, com ajustes e reajustes contínuos que resultam de novos níveis desejados de privacidade e das tentativas de mantê-los. ${ }^{2}$

Os pacientes foram abordados e convidados a tomar parte do estudo no período de hospitalização, respeitando a condição de exaustão dos dados. Desse modo, participaram 34 sujeitos com idade $\geq 18$ anos, de ambos os sexos, conscientes e orientados, internados pelo mínimo de três dias em seis hospitais de Maringá-PR, entre 15 de abril e 25 de maio de 2007, sendo caracterizados quanto à idade, sexo, cor da pele, religião, estado civil, renda familiar, nível de escolaridade, número de internações, tempo da internação atual e nível de dependência. Avaliou-se a dependência em total ou parcial e em Total-Fazer, Parcial-Ajudar, Orientar, Supervisionar e Encaminhar, cuja classificação dimensiona a dependência em graus. ${ }^{7}$ Os valores atribuídos foram baixa dependência, média dependência, alta dependência e dependência total.

A entrevista, semiestruturada, foi orientada pela pergunta: o que é para o(a) senhor(a) privacidade física, com relação à exposição e manipulação do seu corpo, durante a assistência no ambiente do hospital? A questão foi lida para o sujeito e as dúvidas esclarecidas, orientando para se obter o máximo de informações, sem induzir a resposta. Ao final, as anotações, registradas por escrito pela pesquisadora, foram lidas para retificação, complementação e confirmação, sendo transcritas e codificadas após o encontro.

\section{RESULTADOS E DISCUSSÃO}

Evidencia-se, na Tabela 1, a prevalência de pacientes casados (58,8\%), católicos $(70,6 \%)$ e de cor branca $(67,6 \%)$. A maioria tem baixo nível de escolaridade e renda familiar inferior a cinco salários mínimos, verificando-se equivalência quanto ao sexo e à idade. Observa-se ainda na Tabela 2, que a maioria estava internada pelo período de três a seis dias $(61,8 \%)$, não vivenciava a primeira internação e era pouco dependente (53\%).

Tabela 1 - Caracterização sócio-demográfica dos 34 pacientes internados. Maringá-PR, 2007

\begin{tabular}{|c|c|c|}
\hline Dados Pessoais & $\mathbf{n}$ & $\%$ \\
\hline \multicolumn{3}{|l|}{ Sexo } \\
\hline Feminino & 19 & 55,9 \\
\hline Masculino & 15 & 44,1 \\
\hline \multicolumn{3}{|l|}{ Estado marital } \\
\hline Casado & 20 & 58,8 \\
\hline Solteiro & 6 & 17,6 \\
\hline Divorciado & 4 & 11,8 \\
\hline Viúvo & 4 & 11,8 \\
\hline \multicolumn{3}{|l|}{ Faixa etária } \\
\hline 20 a 29 anos & 7 & 20,6 \\
\hline 30 a 39 anos & 4 & 11,8 \\
\hline 40 a 49 anos & 5 & 14,6 \\
\hline 50 a 59 anos & 7 & 20,6 \\
\hline 60 a 69 anos & 4 & 11,8 \\
\hline 70 a 79 anos & 4 & 11,8 \\
\hline$>80$ anos & 3 & 8,8 \\
\hline \multicolumn{3}{|l|}{ Religião } \\
\hline Católica & 24 & 70,6 \\
\hline Protestante & 9 & 26,4 \\
\hline Outra & 1 & 3,0 \\
\hline \multicolumn{3}{|l|}{ Cor da pele } \\
\hline Branca & 23 & 67,6 \\
\hline Negra & 4 & 11,8 \\
\hline Mulata & 7 & 20,6 \\
\hline \multicolumn{3}{|l|}{ Escolaridade } \\
\hline Não alfabetizado & 4 & 11,8 \\
\hline Ensino fundamental incompleto & 13 & 38,2 \\
\hline Ensino fundamental completo & 5 & 14,6 \\
\hline Ensino médio incompleto & 3 & 8,8 \\
\hline Ensino médio completo & 4 & 11,8 \\
\hline Ensino superior incompleto & 1 & 3,0 \\
\hline Ensino superior completo & 4 & 11,8 \\
\hline \multicolumn{3}{|l|}{ Renda familiar } \\
\hline Até 2 salários mínimos & 13 & 38,1 \\
\hline 3 a 5 salários mínimos & 15 & 44,1 \\
\hline 6 a 9 salários mínimos & 3 & 8,9 \\
\hline Acima de 10 salários mínimos & 3 & 8,9 \\
\hline
\end{tabular}


Tabela 2 - Caracterização dos 34 pacientes referente ao período de internação. Maringá-PR, 2007

\begin{tabular}{lrc}
\hline Dados de Hospitalização & $\mathbf{n}$ & $\%$ \\
\hline Tempo de internação atual & & \\
3 a 6 dias & 21 & 61,8 \\
7 a 10 dias & 8 & 23,5 \\
11 dias ou mais & 5 & 14,7 \\
Número de internações & & \\
1 a 3 vezes & 20 & 58,8 \\
4 a 7 vezes & 7 & 20,6 \\
8 vezes ou mais & 7 & 20,6 \\
Nível de dependência & & \\
Baixo & 18 & 53,0 \\
Médio & 10 & 29,4 \\
Alto & 6 & 17,6 \\
\hline
\end{tabular}

A análise das informações emitidas pelos sujeitos evidenciou quatro categorias temáticas: dignidade e respeito, intimidade e toque, autonomia e espaço pessoal e territorial.

Dignidade e respeito é a categoria que se reporta aos sentimentos e reações dos pacientes relativos à exposição e contacto corporal, às preferências segundo suas crenças e valores pessoais, à moral, ao respeito, e ao que consideram uma assistência adequada para resguardar sua privacidade física. Somam-se, ainda, as falas relativas à necessidade de ser visto como ser humano, dono do seu corpo, e não objeto. Isso é importante ante a noção de individualidade e essencial à dignidade, sobretudo se o cuidado envolve a zona corporal.

Em estudo sobre dignidade discutiu-se muito sobre a nudez e visualização dos outros, e a perda da dignidade configurou-se por sentir-se tratado como objeto. ${ }^{8}$ Nesse estudo, ao citar emoções negativas oriundas da exibição e toque corporal, eles indicam desagrado com a situação e atenção à privacidade, presumindo-se que também representem insatisfação com a ação do profissional e fatores que interferiram na privacidade, como se pode conferir nas falas: [...] tenho vergonha, me sinto incomodada, dá agonia, sinto falta de ar [...] (9A); [...] acho ruim porque dá muita vergonha [...] (15A); A gente tem muita vergonha (21C, 32C); Tenho vergonha, mas o que vou fazer? (27A).

Outros estudos apontam emoções similares com relação à condição de nudez e toque corporal, oriundas em grande parte da maneira pela qual os pacientes foram abordados e atendidos. ${ }^{4,8-11}$ Social e culturalmente é impróprio despir-se ante outros, ainda mais se deixar tocar, logo, não será menos desagradável na doença e hospitalização, onde pessoas e ambiente são desconhecidos. Embora al- guns sujeitos tenham manifestado contrariedade, outros encararam a nudez e toque corporal com naturalidade, talvez por realmente não se importar, porque a abordagem foi adequada ou ainda porque considerem como inevitável: [...] a gente acostuma com isso aqui no hospital [...] (10D); [...] já acostumei, são profissionais, é assim mesmo [...] (12C); [...] primeiro achava ruim, tinha vergonha, depois acostumei (25D); Não fico com vergonha deles (30B).

Paralelamente, a atenção de alguns profissionais, a maneira polida de se dirigir ao paciente, bem como o que o ele considera um bom cuidado, contribuiu para uma visão positiva da privacidade física. Deduz-se que isso se deva ao fato de que muitos pacientes se sentiram respeitados $\mathrm{e}$ valorizados pela equipe, e apesar de esperarem respeito à privacidade, entendem que em alguns momentos sua transgressão é necessária, visto que na visão deles: [...] eles são educados, pedem permissão para mexer na gente [...] (13A); [...] respeitam bastante, sempre pedem para examinar e abrir minha camisola [...] (14D); Quando mexem na gente eles falam "dá licença que eu vou examinar a senhora". Daí você tem privacidade (32D); [...] os médicos e enfermeiras pedem licença para entrar no quarto [...] (33B).

Pedir permissão para despir e tocar valoriza o paciente, como ser único e peculiar, e que seu corpo está sob seu domínio. Para eles essa atitude e o respeito conferem dignidade, contudo outros alegam desconsideração por suas preferências para obter privacidade por parte de alguns profissionais em certas ocasiões. De certa forma, eles advertem que são donos e responsáveis por si, que manter a dignidade preserva a identidade moral e a autonomia, e crêem que com permissão não há violação da privacidade, logo, não há perda da dignidade. Um estudo evidenciou que a maioria dos profissionais não tem ciência ou responsabilidade de que deve mostrar respeito pela privacidade e dignidade dos pacientes, sendo isto tido como menos relevante do que o cuidado ou tratamento..$^{12}$ Descaso esse comum na maioria dos serviços, o que se confirma quando os pacientes contam que: [...] chegam tirando minha roupa quase todos os dias, tem enfermeira que nem pede autorização [...] (15D); Muitas vezes abrem minha camisa sem pedir licença. Isso eu considero muita falta de respeito (16A); [...] ninguém pede licença [...] (31B); No hospital ninguém respeita isso, é complicado. Acho que tem que ser repensado sobre isso. Os profissionais precisam ser treinados para respeitar mais seus pacientes (34B).

No hospital a pessoa vivencia eventos que violam a privacidade e agridem a dignidade “[...] 
não pelos atos em si, mas pela forma como estes se desenvolvem" ${ }^{13: 21}$ Por isso o "respeito pode e deve ser entendido como a arte da conduta"13:21 e "emerge como o primeiro princípio ético da enfermagem", , 13:21 respaldando atitudes e direcionando condutas, pois "respeitar é transmitir, através de aceitação incondicional, o reconhecimento dos valores e crenças" 13:21 das pessoas. O respeito à integridade garante a dignidade e também pode ser compreendida como o direito à esfera íntima em relação aos aspectos físicos (determinadas partes do corpo) e psicológicos (certos valores, opiniões e pensamentos) da pessoa. ${ }^{14}$

Intimidade e toque, próxima categoria, se refere à privacidade física como necessidade de poupar o corpo da visão e manipulação dos outros, sobretudo partes íntimas. A maioria dos pacientes expressou desconforto perante contato íntimo, o que se acentua mediante genitália e mamas, sem contar o fato de estar em enfermaria, o que predispõe mais à observação externa. Falas como: [...] é ruim ser trocado por outra pessoa [...] (4A); [...] tenho vergonha quando tomo banho no leito [...] (2A); Me sinto mal por ficar pelada na frente da enfermeira. Não estou acostumada a ter alguém ajudando e me vendo no banho (13C); Privacidade é o que falta aqui. Às vezes levantam minha coberta, pegam em tudo, vai aparecendo tudo (31A); O banho é problema, tenho vergonha, sou das antigas (32A), ratificam essa inferência.

O território corporal inclui o corpo e o espaço abarcado por ele, eé considerado o mais inviolável dos territórios pertencentes à pessoa. Infelizmente, no hospital geralmente o paciente sente-se desapossado do seu corpo, pois em virtude da doença submete-se aos profissionais e abre mão da sua esfera mais íntima, física e psicológica. Nas falas é percebível em que medida isso pode ser agressivo, notando-se também indiferença por parte dos profissionais. Um estudo relatou insensibilidade e desrespeito da equipe à individualidade durante banho no leito, como ignorar o constrangimento, e que ainda é evidente o despreparo da enfermagem para contornar problemas oriundos da exposição e manejo corporal do paciente. ${ }^{4}$ Resultados similares, envolvendo os sentimentos dos pacientes, emergiram em estudos sobre esse e outros procedimentos implicando a nudez do paciente. ${ }^{9-11}$

O cuidado invariavelmente envolve tocar o corpo do paciente e muitas vezes a nudez. São compreensíveis o embaraço e retraimento por implicar intimidade, relação que eles não tem com a equipe e que vem sendo investigada, admitindo-se que o conceito é complexo por abranger aspectos de cunho muito particular, além dos socioculturais. ${ }^{15}$ Por outro lado, entendese que esta relação capacita o profissional para compreender o paciente, encorajar o diálogo, revelar sentimentos e pensamentos, conquistar sua confiança e a troca de informações. Isso é importante quando intimidade envolve não só confidência, mas também o corpo durante o cuidado, pois permite conhecer os desejos do paciente referentes à nudez. Ao investigar intimidade na relação enfermagem-paciente evidenciou-se que o toque íntimo é uma função reconhecida por criar dificuldades na prática da enfermagem, para a qual o corpo é fundamental. ${ }^{15}$

Destarte, intimidade requer negociação e manejo cuidadoso de potenciais conflitos, situações complexas e embaraçosas. Isso é visível nas falas que expressam ultraje ante o contato corporal e à falta de privacidade. Nem todos são receptivos ao toque. Na esfera familiar e social o tocar lembra carinho, afeto, e tais sentimentos não são compartilhados com todos que se convive, e pode até aludir abuso ou ofensiva dependendo do autor do toque, da intenção e do contexto. Por tais razões, além das culturais, as pessoas têm prevenção ao toque e esse deve ser efetuado com cautela, sobretudo quando implica partes íntimas, fato comum no cotidiano da saúde, conforme depoimentos que expressam:[...] ruim mesmo é fazer o preventivo, o exame ginecológico, morro de vergonha $[. .].(32 \mathrm{E}) ;[. .$.$] só tenho vergonha quando$ tenho que ser examinada [...] (33C); Quando o médico pediu para tirar a calcinha por causa da cirurgia, quis sair correndo, sou muito vergonhosa. E quando tem de tirar o sutiã e a blusa? É ruim (33D).

Os pacientes deixam claro que a nudez e o toque fazem parte da sua esfera íntima e que os profissionais não estão incluídos entre os que podem usufruir tal privilégio. São nítidos o desconforto e contrariedade, mesmo quando alguns expressam, indiretamente, entender que a nudez e a manipulação são necessárias naquele momento. Em adição, dois pacientes manifestaram desagrado com o sexo do cuidador ou de outra pessoa presente: [...] tomei banho na frente de dois rapazes. Não deram banho, mas acompanharam o tempo todo [...] (28A); $\mathrm{Na}$ hora do banho minha esposa não estava pra me ajudar. A enfermeira veio e já foi tocando meu corpo. Me cobri, queria mandar ela embora, não gostei disso (34A).

Diferentes estudos evidenciaram a preferência por cuidador do mesmo sexo, sobretudo em situações que exigem expor e manusear partes íntimas,,$^{4,8,15-16}$ sendo isso mais comum entre jovens 
e mulheres, porém, para a maioria o nível e a natureza da intimidade é preditor de preferência por cuidador do próprio sexo. ${ }^{16} \mathrm{Um}$ paciente sutilmente manifestou desconforto à presença de pessoa de outro sexo durante cuidado e outro foi mais enfático sobre contato corporal por profissional do sexo oposto, notando-se que os fatos citados envolvem genitália. Certamente, o caráter mais íntimo gerou a insatisfação com o sexo do cuidador. Compreender intimidade no meio assistencial é crucial dado que em alguns casos privacidade e intimidade são tidos como unívocos. Nesse sentido, o respeito à dignidade, à integridade e à privacidade são imperativos à prática da enfermagem e demais profissionais da saúde. Na verdade, essas concepções e reflexões resgatam a moralidade, o discernimento entre certo e errado, e de colocar-se no lugar do outro para, então, perceber como se deveria conduzir a ação.

Reclamações do tipo: [...] prefiro shorts, não descobre. Usar camisola é ruim porque descobre a qualquer movimento [...] (23C), não são raras em hospitais, ainda mais sobre as roupas com abertura nas costas, pois abrem facilmente, expondo nádegas, mamas, genitália, sem contar os pacientes mantidos no leito só com lençol, o que gera apreensão devido a um possível descuido que permita a visão de outros. Apesar da exposição e toque corporal serem reais no ambiente hospitalar, isso não quer dizer que possa ocorrer indiscriminadamente, visto que a maioria dos pacientes divide enfermaria.

Em contrapartida, outros pacientes sentiramse bem com a atenção recebida, pois manifestaram: [...] não ligo na hora do banho, não me importo [...] (22D); Com relação à exposição me sinto confortável, o banho é normal, não sinto diferença (26B); [...] no banho acho tudo muito profissional [...] (31C). Os homens parecem menos inibidos que as mulheres, pois a eles basta cobrir genitália e nádegas e a elas cabe ainda proteger o tórax. Obviamente isso se deve à educação familiar e aos costumes sociais, já que culturalmente elas são mais reprimidas do que os homens.

Ao tocar o paciente, sugere-se ao profissional estar alerta ao valor pessoal que permeia a interação, ao temor, idade, sexo, classe social, respeitar as diferenças culturais e avaliar com cuidado a reação para determinar uma abordagem aceitável. Nem todo toque é interpretado positivamente, por isso é importante estar ciente do seu efeito. Alguns também expressaram desagrado por ficar exposto à vista daqueles que não faziam parte da equipe ou que não estavam envolvidos diretamente com o cuidado, por estar em quarto coletivo ou negligência do profissional, em função da intrusão do espaço pessoal e territorial.

Tal categoria refere-se ao local e à área ocupados pelo corpo de uma pessoa,,$^{2-3}$ no caso, pelo paciente no ambiente do hospital, os quais podem comprometer a privacidade física quando são compartilhados ou invadidos por outras pessoas, sobretudo na vigência da exposição e manipulação corporal durante a assistência. Afirmativas como: $O$ fato de ter plano enfermaria e ter que dividir quarto prejudica a privacidade (10A); [...] ter que dividir quarto com outras pessoas é ruim [...] (4B); [...] não tem muita privacidade porque tem muitas pessoas juntas [...] (10E), demonstram isso.

Infelizmente poucos têm o privilégio de internar em quarto individual, tanto no Brasil como em outros países. Os pacientes advertem para quão difícil é manter a privacidade em cômodo compartilhado, onde a circulação é constante e que tanto os profissionais como as outras pessoas agem como se entrar e sair fossem normais. Eles expressam, implicitamente, que esperam mais esforço da equipe, e aqui se entende que cabe mais à enfermagem, em adotar medidas que os preserve da visão dos outros, principalmente ante a exposição corporal, visto que: [...] toda hora tem entra e sai para medicação ou visita [...] (1B); [...] tem gente que entra na hora do banho no leito [...] (12B); Âs vezes o quarto enche de gente e me vêem tomando banho (15C); Não fica nem duas horas sem entrar alguém no quarto para trocar medicamento, soro, coletar urina (28G).

Outro estudo, realizado com idosos institucionalizados, evidenciou que se importam mais com a intromissão do espaço pessoal do que com a invasão do espaço territorial, e que dentre os eventos considerados por eles como mais desagradáveis foram aqueles em que houve exposição de partes íntimas durante execução de procedimentos. $^{9}$

Reconhece-se que a incursão no quarto ou banheiro, quando se está despido, caracteriza-se como invasão da privacidade, tendo em vista que o que os pacientes requerem é impedir o trânsito nesses momentos, trancando a porta, colocando aviso, proteger o leito com biombos ou cortinas, pois a angústia provocada pela probabilidade de alguém entrar é visível, sobretudo ao enfatizar os problemas com o banheiro como [...] privacidade é ter o banheiro fechado [...] (22A); No banheiro quero privacidade, aqui ou em qualquer outro lugar, só que aqui não tem como (34C); [...] entram no banheiro para tirar o soro [...] (28D). 
A enfermagem comumente viola o espaço e território do paciente por não avisar antes de exceder os limites, por sobrecarga de trabalho ou dificuldade com os obstáculos e com a deficiência de recursos. ${ }^{17}$ Territorialidade provê segurança, privacidade, autonomia e identidade ${ }^{2-3} \operatorname{logo}$, é compreensível que o paciente vislumbre a intromissão como ameaça à sua integridade: [...] às vezes abrem a janela quando estou sem roupa [...] (15E); As enfermeiras e o pessoal da limpeza tem o costume de entrar, sair, e deixar a porta aberta. Tem que ter o cuidado de fechar a porta $(28 \mathrm{H})$; ou ainda porque [...] aqui não tem a privacidade da casa da gente [...] (9C); [...] no hospital não tenho direito ao meu espaço [...] (10F); Gosto de ter o meu cantinho (33E).

Percebe-se a inquietação provocada pela ausência de local exclusivo, de tempo para reclusão íntima, sem risco de interrupções inoportunas. No hospital sempre ocorre invasão do espaço pessoal e territorial, contudo os pacientes precisam de isolamento, cujo artifício é um meio de controlar seletivamente a interação social e o acesso a si. ${ }^{2}$ Ainda assim, uma minoria não se importa com a presença de outros, fato incomum, talvez por não terem sua privacidade infringida a ponto de gerar apreensão, pois disseram que: [...] não incomoda ter outras pessoas no quarto [...] (7B); Às vezes porta aberta também é necessária, quando não tem acompanhante para olhar (28J); Não me sinto invadida por ficar no quarto com outra pessoa. Você pode conversar (32F).

Privacidade espacial e territorial é uma necessidade básica do ser humano ${ }^{2-3}$ e em situações especiais, como doença e propensão à exposição corporal, é ainda mais vital à integridade pessoal. Supõe-se que alguns possam lançar mão de barreiras psicológicas contra a intrusão, ${ }^{3}$ ou apenas aceitar o fato por não ver alternativa. O depoimento de vários pacientes evidencia que relacionam privacidade ao controle sobre o próprio corpo, sobre a situação em que esse é submetido à visão dos outros, e também ter poder para tomar suas próprias decisões, tentando resgatar o direito a autonomia, última categoria.

Ao referir-se à privacidade como controle eles sinalizam que não tiveram direito de escolha. Acatam tudo por entender que impera o domínio profissional, a rotina do serviço e a primazia ao tratamento. Isso é visível quando falam: [...] é melhor deixar fazer tudo que precisa, tem que examinar. É para nosso bem [...] (9B); [...] tem que ser feito. Eles estão trabalhando [...] (11B); [...] o que tem que fazer é necessário [...] (23A); Os médicos vêm visitar e não adianta esconder. Se eles pedem para tirar a roupa, tem que tirar. Se estiver passando mal tem que deixar $(27 \mathrm{H})$.

Ser capaz de determinar como, onde, quando e por quem seu corpo vai ser despido e tocado, é uma forma de controlar o acesso físico, o que confere independência e poder para decidir por si e para si. O fato de precisar ficar desnudo e de ajuda denuncia dependência, compromete sua autonomia, e, por conseguinte, sua privacidade. Afinal, a invasão ocorre quando o indivíduo é inábil em prevenir o acesso físico a si e porque nem todos que desejam alcançar privacidade têm habilidade para obtê-la. ${ }^{18}$ Isso pode levar a pessoa a sentir-se incompetente no que se refere à própria privacidade e, logo, em manter sua integridade física.

Exercer o direito de escolha parece minimizar a sensação de descontrole sobre si, o que é perceptível ante a perspectiva de optar segundo sua preferência, como: [...] enquanto puder, faço tudo sozinha [...] (14A); Autorizo os procedimentos para o correto diagnóstico visando a melhora da saúde (18A); Ao procurar assistência médica o paciente precisa estabelecer uma parceria com os profissionais para o bom andamento do tratamento, mesmo que este exponha parte do seu corpo (19A).

A sensação de domínio, que a opção é sua, faz com que a pessoa se sinta respeitada e segura ao permitir a violação da privacidade, a qual se distingue pelo senso de limite entre eu, mim e meu e outra pessoa e o mundo. ${ }^{12}$ Um estudo observou falta de privacidade para higiene e uso de roupa hospitalar, que sempre desnudavam seios e genitais, e identificou a necessidade de controle e opção individual para obtê-la, notando-se que os pacientes têm pouca chance de escolher. Aponta, ainda, que eles aceitam a falta de privacidade no hospital, nas enfermarias, sem protestar para não serem tidos como impopulares, e que acatam ter menos privacidade por priorizar as necessidades médicas e crer que o cuidado é mais importante do que preservar a privacidade. ${ }^{12}$

Igualmente, os pacientes admitem que se sujeitam porque o acesso a seu corpo pode esclarecer seu problema e definir o rumo do tratamento, e que se submetem à ação do profissional por crer que o saber deles está acima da sua necessidade por privacidade. Essa revelação fica clara ao colocarem: - se as pessoas não se expõem não tem como os médicos e enfermeiras saberem o que a gente tem. Deixo me examinarem porque é serviço deles. Quero me curar (8C); [...] tenho que deixar, sabem o que estão fazendo [...] (12D); Tem que ficar pelada para exame e destampar o corpo porque é o correto para o profissional ver (25B). 
Eles superestimam o conhecimento, a capacidade e autoridade dos profissionais, confiando que deles partirá, integralmente, a solução para seus problemas. É visível que nem cogitam protestar, abrindo mão de escolher, de decidir sobre si. Os mecanismos de poder disciplinar vigentes no hospital viabilizam o acesso ao corpo do paciente, "manipulando-o, invadindo-o, sem abrir espaço para reações ou questionamentos", ${ }^{19: 114}$ ou seja, a internação "representa uma autorização" 19:108 para que a equipe tenha livre acesso ao seu corpo. Sugere-se oportunizar ao paciente tomar decisões e delegar certas atividades, pois a qualidade da relação equipe-paciente depende da competência ética e da atitude profissional em resposta à singularidade de cada paciente, e da particularidade e imprevisibilidade de cada situação. ${ }^{14}$

Entende-se que aptidão ética também implica sensibilidade profissional para saber até onde ir, o que fazer, quais são os limites e, sobretudo, perceber a insatisfação dos pacientes, já que alguns reclamaram da diferença de sexo e do grau de parentesco em certos eventos: [...] se for homem não gosto muito não [...] (25E); [...] filha e filho não gosto, porque mesmo sendo mãe é chato [...] (27E); No quarto são minhas filhas que ajudam, não são os enfermeiros (28C); No banho prefiro minha filha, se fosse um homem cuidando de mim eu já tinha ido embora (32B).

Enquanto alguns preferem familiares outros não apreciam, pois a proximidade nem sempre favorece a relação de cuidado, ao contrário, às vezes essa condição é ainda mais embaraçosa. Ao mesmo tempo, a equipe parece ignorar o sexo do paciente, sobretudo a enfermagem, talvez ajam desse modo por pensar ser mais fácil o acesso ao corpo dele, ou por acreditar que para ele assim será menos agressivo, ou significa que empreendem um mecanismo de defesa contra aquilo para o qual não estão preparados para enfrentar ou contornar. Alerta-se que encarar o paciente como assexuado denota desrespeito ao seu pudor, sua intimidade e privacidade. ${ }^{11}$

\section{CONSIDERAÇÕES FINAIS}

Percebe-se que as razões de inquietação relativas à privacidade, assim como as expectativas dos pacientes com várias internações anteriores, em comparação às daqueles que vivenciam a primeira ou segunda internação, são similares. $\mathrm{O}$ mesmo foi observado quanto à idade, estado civil, religião, nível de escolaridade e condições sócioeconômicas. É visível a preocupação acentuada com a nudez, sobretudo mediante contato corporal e área íntima, predisposição à visão de outros que não sejam da equipe ou que sejam do sexo oposto, sendo isso mais enfático entre as mulheres e nos pacientes mais dependentes.

Nota-se, também, que à medida que se prolongam os dias de permanência no hospital, que quanto maior a necessidade por cuidados corporais e maior o grau de dependência, o risco de ter o corpo desnudo tocado e manipulado aumenta proporcionalmente e, nesse caso, os pacientes são mais enfáticos a respeito das transgressões contra sua privacidade. Certamente, porque nessa condição estão mais sujeitos às ações dos profissionais e às circunstâncias que os predispõem à violação da privacidade.

Assim sendo, sob a ótica dos pacientes, privacidade física está interligada com dignidade e respeito, demanda relação de intimidade por envolver o toque corporal, depende de espaço territorial e pessoal e garantia de autonomia. A concepção deles sobre privacidade corporal tem conexão com as condutas e atitudes que os dignifica, considerando os aspectos que permeiam a esfera íntima. Destacam que a abertura do espaço pessoal e territorial aumenta as chances de pessoas inapropriadas visualizarem seu corpo desnudo e enfatizam a importância de nessas ocasiões poder controlar a situação e o acesso a si.

Em síntese, na percepção deles dignidade, respeito, intimidade, toque corporal, autonomia, espaço pessoal e territorial são conceitos interrelacionados, inerentes e imprescindíveis à proteção e manutenção da privacidade, especialmente na vigência da exposição e manipulação do corpo durante a assistência. Deduz-se que, se os profissionais da saúde observarem e considerarem esses aspectos ao realizarem as atividades de cuidado, a sensação de invasão da privacidade pode ser minimizada, mesmo frente a nudez e contato corporal íntimo.

Embora os resultados deste estudo tenham implicações para a prática profissional, sobretudo da enfermagem, a visão dos pacientes entrevistados não pode e nem deve ser generalizada para outros contextos, mas certamente servem de base para futuras investigações e como orientação para as pessoas envolvidas com a assistência à saúde. Destaca-se, ainda, que os princípios éticos permeiam as condutas e os aspectos que afetam a privacidade dos pacientes, ou pelo menos assim o deveria ser, e, portanto, recomenda-se que estes devem respaldar as ações dos profissionais envolvidos com a assistência. ${ }^{5}$ 


\section{REFERÊNCIAS}

1. Pupulim JSL, Sawada NO. O cuidado de enfermagem e a invasão da privacidade do doente: uma questão ético-moral. Rev Latino-am Enfermagem. 2002 MaiJun 10(3):433-8.

2. Altman I. The environment and social behavior: privacy, personal space, territory, crowding. Monterey (US): Brooks/Cole; 1975.

3. Westin A. Privacy and freedom. New York (US): Atheneum; 1970.

4. Pupulim JSL, Sawada NO. Exposição corporal do cliente no atendimento das necessidades básicas em UTI: incidentes críticos relatados por enfermeiras. Rev Latino-am Enfermagem. 2005 Mai-Jun 13(3):388-96.

5. Mendes G. A dimensão ética do agir e as questões da qualidade colocadas face aos cuidados de enfermagem. Texto Contexto Enferm. 2009 Jan-Mar 18(1):165-9.

6. Bardin L. Análise de conteúdo. Lisboa (PT): Edições 70; 2000.

7. Horta WA. Processo de Enfermagem. São Paulo (SP): EPU/EDUSP; 1979.

8. Walsh K, Kowanko I. Nurses' and patients' perceptions of dignity. Int J Nurs Pract 2002; 8:143-51.

9. Prochet TC, Silva MJP. Proxêmica: as situações reconhecidas pelo idoso hospitalizado que caracterizam sua invasão do espaço pessoal e territorial. Texto Contexto Enferm. 2008 Abr-Jun 17(2):321-6.
10. Figueiredo NMA, Machado WCA. A nudez do cliente: $\mathrm{o}$ (des) equilíbrio no cuidado de enfermagem. Rev Enferm UERJ. 1996 Dez 4(2):143-52.

11. Silveira MFA. Estar despido na UTI: duas percepções, um encontro. Rev Enferm UERJ. 1997 Dez 5(2):449-59.

12. Woogara J. Patients' privacy of the person and human rights. Nurs Ethics. 2005; 12(3):273-87.

13. Catarino J, Cassiano J, Silva RC. O respeito como princípio moral básico e principal princípio em enfermagem. Nursing. 1996 Abr; 99(9):21-4.

14. Randers I, Matiasson AC. The experiences of elderly people in geriatric care with special reference to integrity. Nurs Ethics. 2000; 7(6):503-19.

15. Dowling M. The sociology of intimacy in the nursepatient relationship. Nurs Standard. 2006 Feb; 20(23):48-54.

16. Chur-Hansen A. Preferences for female and male nurses: the role of age, gender and previous experience - year 2000 compared with 1984. J Adv Nurs. 2002; 37(2):192-8.

17. Malcolm HA. Does privacy matter? Former patients discuss their perceptions of privacy in shared hospital rooms. Nurs Ethics. 2005; 12(2):156-66.

18. Margulis ST. Privacy as a social issue and behavioral concept. J Soc Issues. 2001; 59(2):243-61.

19. Ferreira MA, Figueiredo NMA. Os mecanismos disciplinadores do hospital. Esc Ana Néri Rev Enfermagem. 1997 Set; 1(1):103-16. 